\title{
Methods for measuring transport noise in the city street and road network
}

\author{
Fitrat Abdikhalilov oglu*, and Asadulla Khotamov \\ Civil Engineering Institute, Tashkent, Uzbekistan
}

\begin{abstract}
This study analyzes the speed of traffic on city streets and the level of noise from vehicles. In terms of objects: To determine the amount of traffic and the level of noise on Nurafshan and Nukus streets in Tashkent, the intensity of traffic during peak hours was studied. Based on the results of in-kind experiments, the following conclusions were drawn: Despite the increasing density of the road network in Tashkent, the level of congestion on these streets is very high (more than 2400 cars / hour on each side). More than $95 \%$ of moving vehicles are cars. The level of noise from vehicles along the construction line on these streets is $18-20 \mathrm{DBa}$ above the sanitary norm in the morning rush hour. This study analyzes the speed of traffic on city streets and the level of noise from vehicles. At the same time, the problem of density of the street network in Tashkent, the results of its comparison with the density in some cities of developed countries.
\end{abstract}

\section{Introduction}

As a result of urbanization in large cities, the demand for public and private transport is growing, along with a sharp increase in population. As a result, a number of economic, social, environmental, sanitary and hygienic conditions are aggravated, such as reduced traffic capacity, reduced traffic speeds, traffic jams at many single-level intersections, lost passenger time, as well as increased emissions and traffic noise.

Despite the fact that Tashkent is a relatively new city - many of the requirements of urban planning are formed in accordance with current standards, today there is a sharp increase in the number of vehicles in the city, including traffic, pedestrian crossings, parking, garages and private cars. as a result, the level of pollution of the city's sanitary condition from traffic noise is also a separate issue. For this purpose, in this case, the data obtained on the basis of the results of in-kind observations of changes in traffic in some streets of Tashkent for the last 3 years $(2018-2021)$.

The optimal solution to the problem of transpoRN in urban planning is formed on the basis of multifactor analysis, in which it is necessary to find a rational solution to complex economic, social, sanitary and environmental issues. Because the perspective development of the master plan of this city is determined by the decisions made earlier. As an indicator of the development of transpoRN infrastructure manifests itself as a manifestation of

\footnotetext{
${ }^{*}$ Corresponding author: abdixalilovfitrat@gmail.com
} 
urbanization, accordingly, the urgency of the issue of transpoRN will increase, especially in large cities.

It is known that the existing road network (RN) in cities is assessed by its density indicator. RN density is determined by the ratio of the length of the existing network $(\mathrm{km})$ to the total area of the city $(\mathrm{km} 2)$. Hence, the throughput of a RN depends on its density index. Establishment of intersections at different levels with the help of two- and multi-tier aRNificial trestle, used in developed countries as a measure to increase the capacity of RN, connecting the main transpoRN hubs of the city (international and domestic stations, airpoRNs ...) with highways; there are experiences such as the construction of multi-storey car parks and the extensive use of the underground environment in this area. The problem of transpoRN in urban planning has become especially acute in large cities, especially in Tashkent. In Tashkent, which has grown almost four times in size over the last century, the density of HVAC is relatively good compared to the world's largest cities, but does not meet the capacity of the network. Therefore, two- and more-level overpasses are being built to increase the capacity of the largest intersections. Such work will increase the density of the road network and the capacity of the network. However, the issue of vtotranspor noise in the urban street network has not lost its relevance as one of the main issues causing discomfoRN in the urban environment. Violation of the sanitary and hygienic condition of the city due to traffic noise, especially in large cities, requires the use of special noise-canceling screen structures. In developed countries, the use of special noise-canceling screen constructions is widespread. Another impoRNant issue is the widespread use of alternative energy sources, especially solar energy. The use of solar energy is now practiced in almost all countries of the world.

In our study, the integration of the two facilities into a single structure, that is, the placement of solar panels in noise-canceling screen structures installed on city streets and roads, is considered. In this way, the solar panels also serve as a noise-canceling screen. As a result, valuable urban space allocated for solar panels is saved, no specially prepared areas are required for the operation of solar panels. It is possible to organize the operation and maintenance of panels placed on a special structure on the sidewalk of the street or road.

The purpose of the project is to install solar panels in noise-canceling screens, which are used to protect residential areas from traffic noise in large cities and residential areas. consists of providing.

The main task of this work is to jointly solve two tasks that are important in modern urban planning to achieve the goal.

The first issue is the fight against traffic noise, which is one of the negative factors in the city, which has increased significantly in recent years, the use of special engineering measures in this area.

The second issue is the use of alternative energy sources in times of energy shortage, which has become a global problem in modern urban planning. Of course, the issue of using natural resources is important.

\section{Materials and methods}

U.S. scientists were the first to monitor and protect against the spread of noise in cities from the middle of the twentieth century. In 1960, the first noise barriers began to be used on the Millipitass Highway in California, USA. As a result of the growth of motor vehicles, largescale scientific research has been conducted around the world to assess the noise on city streets. By the year 2000, a city noise map was created using GIS and GPS technologies. In 2005, the UK developed the world's largest London Road Traffic Noise Map. Later, a noise map of the city was created in Madrid using noise monitoring results at more than 4,000 
points [5]. Currently, there are noise maps of more than 500 cities in Germany, and scientific research has been conducted using GIS technology to develop noise maps of cities in Italy, the Netherlands, Turkey, Japan, South Korea, the United States and Brazil. A number of scientists have developed their own methodology for monitoring and analyzing the propagation of motor noise. In analyzing the noise distribution in Guangzhou, China, scientists Ming Cai, Jingfang Zou, Jiemen Xie [5] developed their own methodology. According to him, several indicators of vehicles, which are the main source of noise in the city, were taken into account. These include: analysis of noise propagation taking into account factors such as traffic speed, vehicle speed, congestion density, optimal density [47].

$$
\begin{aligned}
& \left\{\begin{array}{c}
v=v_{f}\left(1-\frac{k}{k_{j}}\right) \Rightarrow \mathrm{Q}=\mathrm{kj}\left(\vartheta-\frac{v^{2}}{\vartheta f}\right) \\
Q=v k
\end{array}\right. \\
& \left\{\begin{array}{c}
v=v_{m} \operatorname{In} \frac{k_{j}}{k} \\
Q=v k
\end{array} \Rightarrow \mathrm{Q}=\frac{\vartheta k j}{e \frac{\vartheta}{\vartheta m}}\right. \\
& \left\{\begin{array}{c}
v=v_{f} e^{\frac{-k}{k_{m}}} \\
Q=v k
\end{array} \Rightarrow \mathrm{Q}=-v k_{m} \ln \frac{v}{v_{f}}\right.
\end{aligned}
$$

where: $Q$ - traffic speed (auto / hour),

$v$ - vehicle speed $(\mathrm{km} / \mathrm{h})$

$v_{f}$ - free flow rate $(\mathrm{km} / \mathrm{h})$;

$v_{m}-$ critical speed $\mathrm{vm}=\mathrm{vf} / 2(\mathrm{~km} / \mathrm{h})$

$k_{j}$ - traffic density (auto $/ \mathrm{km}$ );

$k_{m}$ - optimal density $\mathrm{km}=\mathrm{kj} / 2$ (auto / km)

$v f$ and $k j$ data recorded in the evening and during the day for 1 month by a special camera installed on the streets;

The main indicators of the quality of road network activity are traffic safety, convenience and economy. These indicators are largely determined by the level of traffic congestion of the road network, ie the ratio between the speed of traffic and its capacity. The intensity of movement varies over time i.e. during the seasonal week and day. The change in traffic intensity during the year is represented by the annual inefficiency coefficient.

$$
\mathrm{K}_{\mathrm{H}}=\frac{W_{\text {month }}}{W_{\text {year }}}
$$

where: $\mathrm{W}_{\text {month- }}$ monthly movement intensity; $\mathrm{W}_{\text {year- }}$ annual movement intensity;

As a result of the observations, the values of the coefficient "K_N" in the example of Moscow for large cities were as follows [7].

Table 1. Indicators calculated by month

\begin{tabular}{|c|c|c|c|c|c|}
\hline January & February & March & April & May & June \\
\hline 0,070 & 0,088 & 0,086 & 0,085 & 0,074 & 0,071 \\
\hline July & August & September & October & November & December \\
\hline 0,065 & 0,066 & 0,094 & 0,014 & 0,097 & 0,100 \\
\hline
\end{tabular}

The change in traffic intensity during the day is mainly to two values at 7:00-9:00 in the morning and 17: 00-19: 00 in the evening. At this time, the townspeople go to and from school, work. The main intensive traffic on the road during the day is observed at this time. The main flight during the day is $12-14$ hours (during). 
The study analyzes the results of observations during the morning rush hour on Nurafshan and Nukus streets in Tashkent. As a result of the observations, a comparative analysis of the hourly traffic intensity on these streets as of the 1st quarter of 2018-2021 is presented in the following diagrams (Figure 1-2).

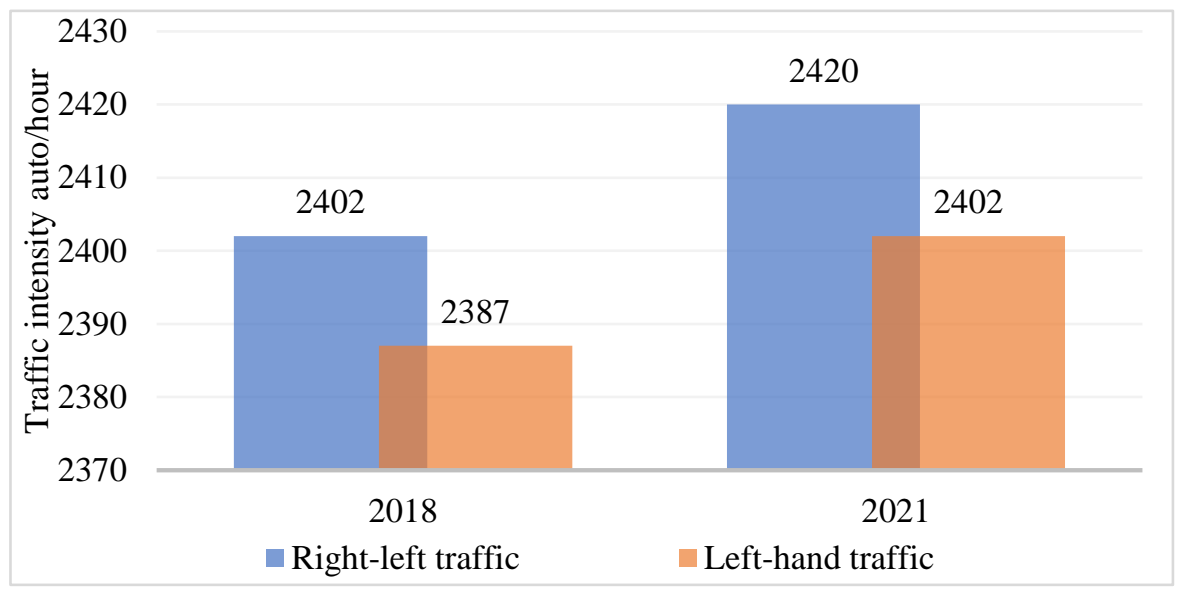

Fig. 1. Comparative analysis of 1-hour traffic on Nurafshan Street in Tashkent for 2018-2021.

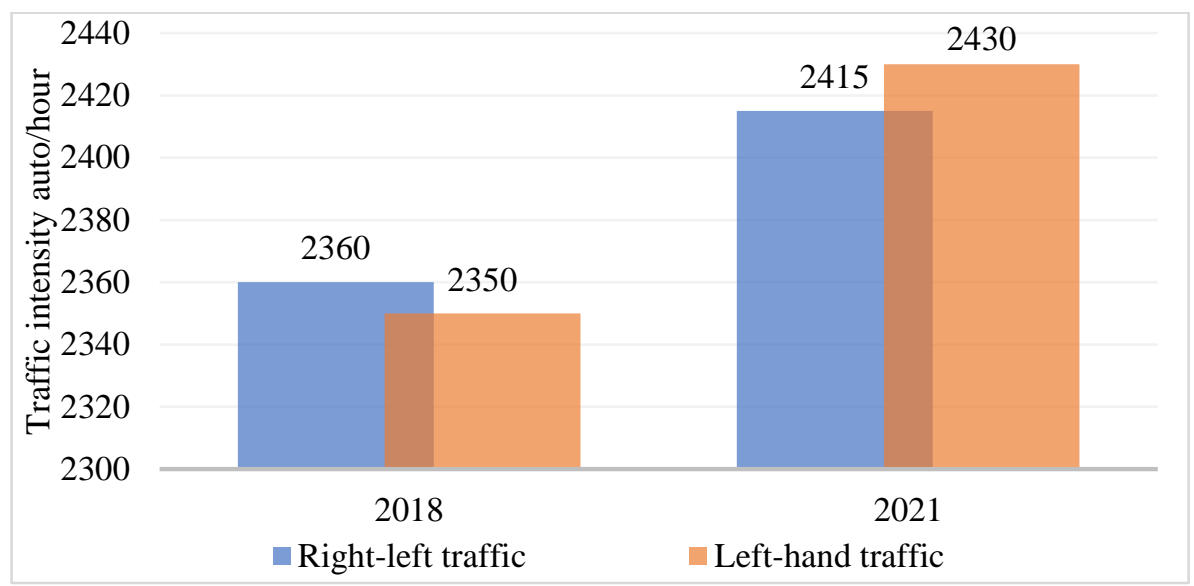

Fig. 2. Comparative analysis of 1-hour traffic on Nukus Street in Tashkent for 2018-2021.

The traffic flow density characteristic is used to calculate the load of a particular street or specific structure (tunnel, trestle, maneuvering area). The throughput of the carriageway and the entire road is usually calculated taking into account the distance between cars. These intervals can be expressed in units of length or time [1]. When the speed is known, the time interval between cars is:

$$
\mathrm{P}_{\text {пол }}=\frac{\boldsymbol{V}_{\text {расч }}}{\boldsymbol{S}_{\min }},
$$

where, $\mathrm{P}_{\text {пол }}$ is the bandwidth of the path band;

$\boldsymbol{V}_{\text {расч }}-$ allowable design speed of a certain category of road (street);

$\boldsymbol{S}_{\text {min }}$ - minimum distance between cars in the stream;

A slightly different approach is needed to perform calculations related to high-speed traffic flows. A minimum interval can be taken as the boundary condition. 


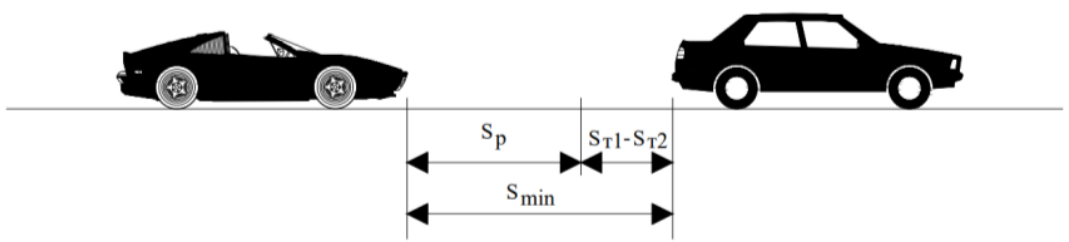

Fig. 3. Scheme for determining the minimum distance between vehicles for high-speed traffic flows.

Thus, the minimum interval between cars depends only on the time of the second car driver's movement and the difference between the stopping (braking) distance of the second and first cars [9].

The term traffic speed on city streets means the amount of traffic passing through a certain section of the road per unit of time. The speed of traffic on the city road network varies over time. Changes are observed according to the season, days of the week and hours of the day. According to the results of the research, based on the data of the State Committee for Motor Roads of the Republic of Uzbekistan in the laboratory of the Unitary Enterprise "Road Project Expertise" and the Traffic Safety Department of the Main Department of Internal Affairs of Tashkent, the average daily traffic on Tashkent public roads was analyzed. A cartogram of the intensity of traffic on the ring road and the small ring road in the city was developed [9-12].

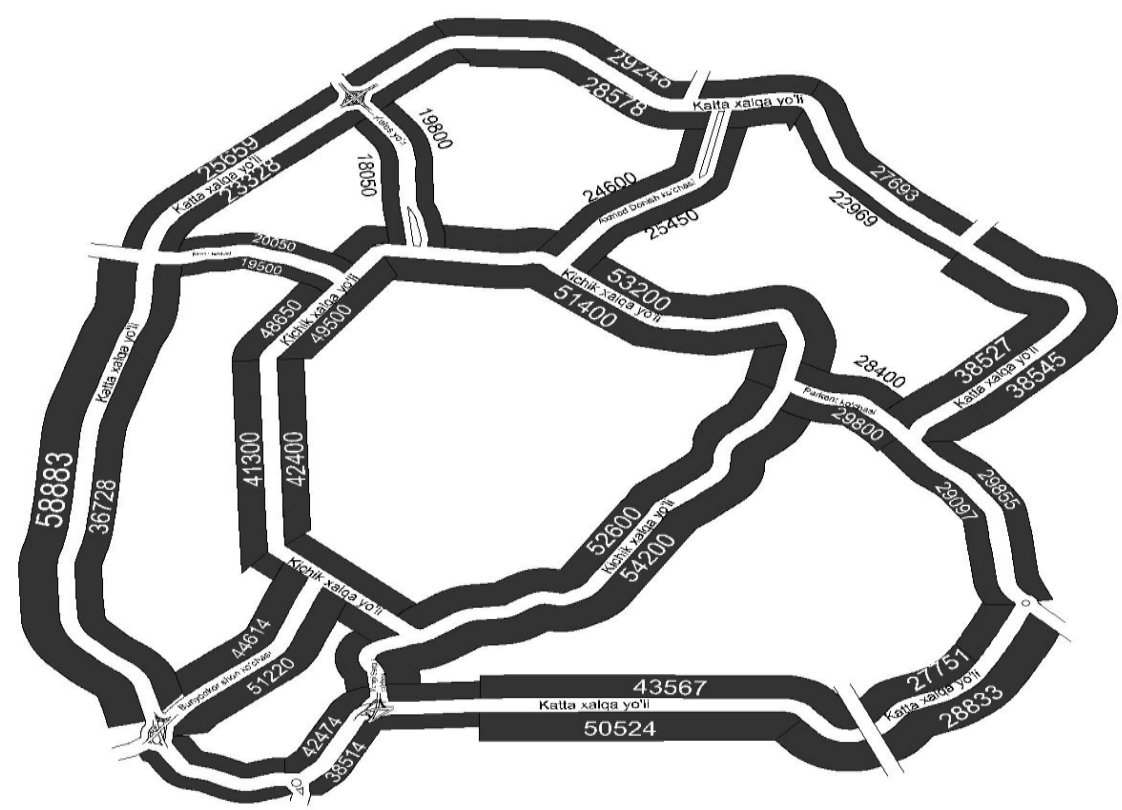

Fig. 4. Tashkent Ring Road, Small Ring Road and the level of traffic on the streets connecting them (unit) (As of January 2019).

Today, the reduction of the noise problem caused by the increase in traffic in cities is one of the current problems in urban planning, the amount of which is growing from year to year. It is known that a sharp increase in noise has a negative impact on people's work and leisure, as well as a number of diseases.

It is known that the main sources of noise in cities are noise on highways. Measurement of noise levels on public roads surrounding urban settlements is carried out on the basis of 
current State Generally Accepted Standards Requirements 20444-85 and State Generally Accepted Standards Requirements 23337-2014 for the regions of the country. At a distance of $2 \mathrm{~m}$ in front of the noise meter is mounted a special device and the device microphone facing the traffic flow. Noise level is measured for a minimum of 20 minutes and a maximum of 30-40 minutes. The degree of equivalence of the traffic flow noise is characterized by $\mathrm{L}_{\mathrm{ekv}}$, DBA [2].

In order to measure traffic noise, it is advisable to measure it at "busy time" on the highway [7].

The noise on the city streets is a chaotic combination of different fog sounds. Waves generated by the vibrations of a sound-emitting body propagate through the air, sometimes condensing and sometimes diluting the air, resulting in sound pressure. However, in cities, the bulk of them are noise from vehicles [13].

The human auditory organs quickly detect and hear sound pressures in the range of sound vibrations from 16 Gts to 20,000 Gts. The sound frequency is measured in GTs and is represented by the number of oscillations per second. For hearing organs, the range of $45 \mathrm{Gts}$ to $10,000 \mathrm{Gts}$ is the most important, it does not accept low-frequency (infra) sounds below $16 \mathrm{Gts}$ and high-frequency (ultra) sounds above 20,000 Gts [14-15]. The relationship between noise level (DBa) at sound frequency (Gts) is shown in the graph below (Figure 5).

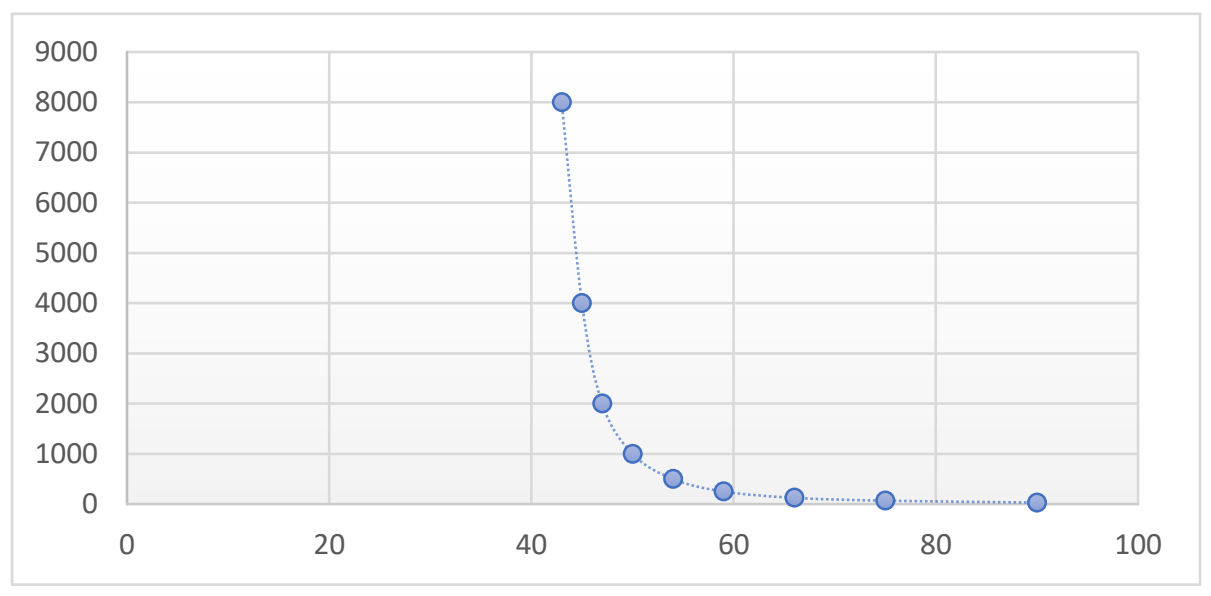

Fig. 5. In accordance with State Generally Accepted Standards Requirements 23337-2014, the relationship between sound frequency (GTs) and noise level (DBA) in residential areas is given: noise level along the abscissa axis (DBa); sound frequency (GTs) along the ordinate axis.

In an experiment conducted in collaboration with the Tashkent State Center for Sanitary and Epidemiological Surveillance (TSCSES), the levels of traffic noise in relation to residential areas on Nurafshan and Nukus streets in Tashkent were studied. Natural observation works As mentioned above, the results obtained from a special device for noise measurement, installed in accordance with State Generally Accepted Standards Requirements 23337-2014 at a distance of $2 \mathrm{~m}$ from the residential building are shown in the following figures (Figures 6-7). 


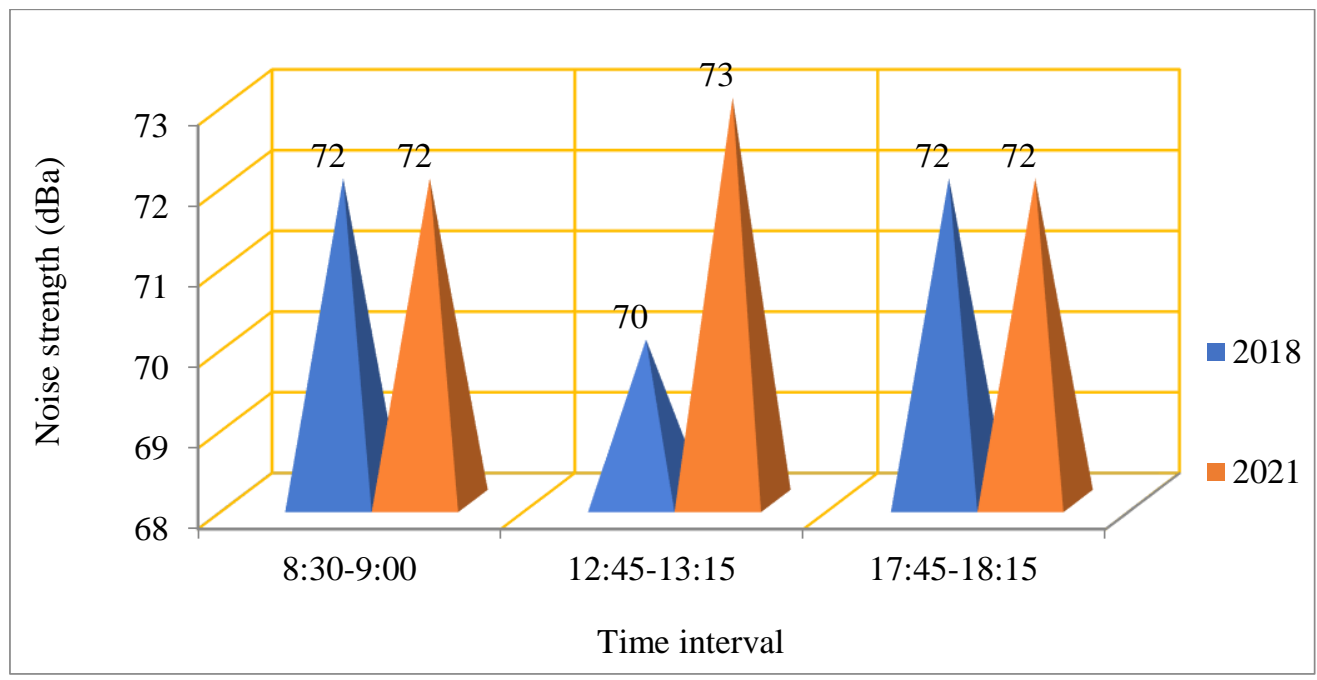

Fig.6. Comparative indicators of noise level (DBa) on Nurafshan Street in Tashkent in 2018-2021.

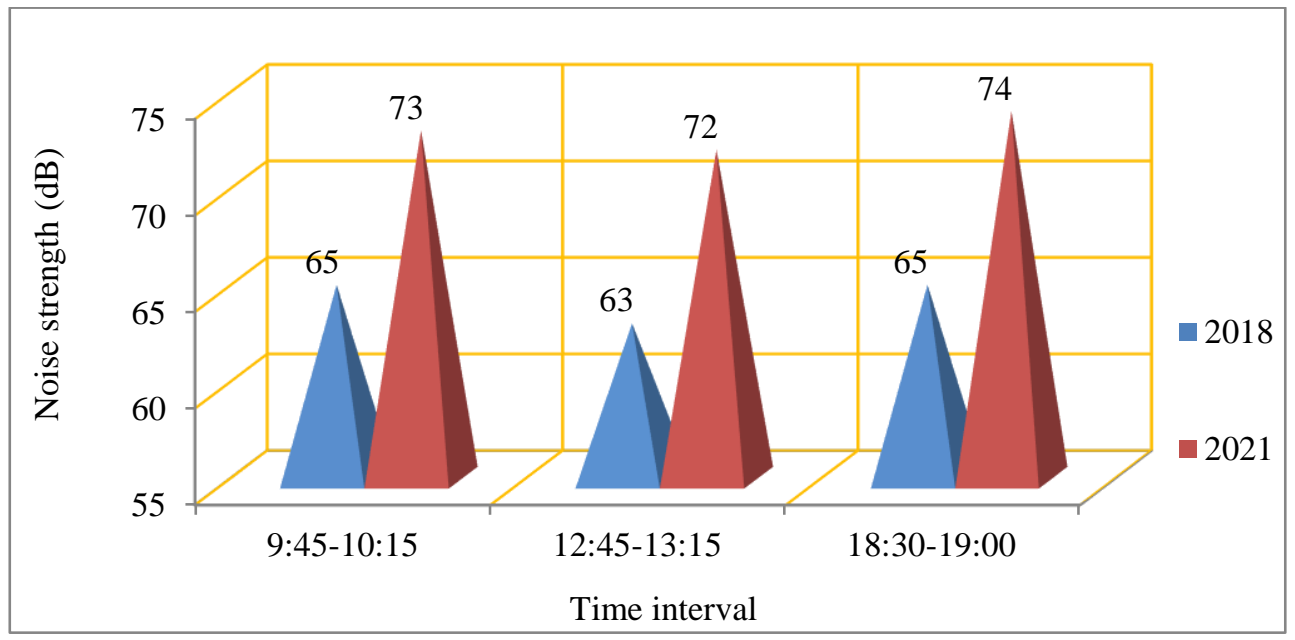

Fig. 7. Comparative indicators of noise level (DBa) on Nurafshan Street in Tashkent in 2018-2021.

\section{Results and discussion}

The dynamics of noise level changes in Nurafshan Street in Tashkent for the last 3 years is as follows:

- from 8-30 to 9-00 - unchanged;

- In the period from 9-45 to 10-15 - increased by\%;

- In the period from 12-45 to 13-15 - increased by\%;

- In the period from 17-45 to 18-15 - increased by\%;

- In the period from 18-30 to 19-00 - increased by\%;

- The results of the experiments show that the level of traffic noise on the street where the experiment was conducted has increased over the past 3 years;

- Despite the increasing density of the road network in Tashkent, the level of congestion on this street is very high (more than 2400 cars / hour on each side);

- More than $95 \%$ of moving vehicles are cars; 
- The level of noise from vehicles along the construction line of this street is 19DBa above the sanitary norm in the morning rush hour;

According to the current norms, the density of $\mathrm{RN}$ is $\delta_{\mathrm{ac}}=2.2-2.4 \mathrm{~km} / \mathrm{km} 2$ with the distance between them being $0.5-1.0 \mathrm{~km}$. In Tashkent, the value of $\delta_{\mathrm{ac}}$ is currently $5-6 \%$ below the norm [14].

The indicator of $\mathrm{RN}$ density in urban planning depends on another important factor, which is the nonlinearity coefficient $\left(\mathrm{K}_{\mathrm{n}}\right)$ of $\mathrm{RN}$. The magnitude of this coefficient depends on the scheme of the city RN. From the experience of world urban planning, it is known that the most optimal scheme in this regard is the diagonal rectangular scheme, which has been used in practice in several new cities in the United States. According to this scheme, $K_{n}=1.1-1.2$. In the ring scheme, this figure is $K_{n}=1.5$ [13].

In Tashkent, we can see a combined scheme, ie the central square zone is radial-ring, while the relatively new zones of the city are organized on the basis of a rectangular scheme. While the high density of RN increases the carrying capacity of vehicles in the city, on the other hand, it requires very large capital investments, as well as reduces the coefficient of efficient use of valuable land in urban development.

It is also known from urban planning experience that there is also a correlation between urban population and $\mathrm{RN}$ density. That is, in small cities, in cities with a population of 100250 thousand people, the density of $\mathrm{RN}$ is around $\delta=1.6-2.2 \mathrm{~km} / \mathrm{km} 2$, while in cities with a population of more than 2 million, this figure is $\delta=2.4-3.2 \mathrm{~km} / \mathrm{km} 2$. It follows that the density of RN relative to the urban population increases in proportion to each population in the city. The city of Tashkent is still far below the average.

\section{Conclusion}

In this study, the deterioration of the sanitary situation under the influence of traffic on the streets of Tashkent, the causes of which are studied on the basis of concrete evidence, and the priorities for solving problems in the transport system and the problems caused by traffic on city streets:

- Due to the lack of street elements (except trays and sidewalks) in the construction (red in the area at the same time) line, ie landscaping along this line, landscaping along this line, construction of special barrier decorative structures, design of ground level at different levels with the carriageway (or economically inefficient);

- In this section, the use of special urban planning and engineering measures to reduce the effect of noise in order to protect residential areas from excessive noise levels is required;

In order to bring the noise level to the sanitary norm, it is recommended to use modern special noise-reflecting screens on this street.

It should be noted that for the first time a map of the intensity of traffic on the ring road and the Small Ring Road in Tashkent was developed, which is important in determining the development and prospects of the city road network.

\section{References}

1. I.A.Bakhirev, Transport problems of the modern city (Urban planning, 2016)

2. State Generally Accepted Standards Requirements, https://www.investopedia.com/fundamental-analysis-4689757

3. B. Greenshields, Proceedings of the Highway Research Board, Transportation Research Board, National Research Council, 14 (1), 467 (1935)

4. C. Ming, Z. Jingfang, X. Jiemen, Applied Acoustics, 87, 94 (2015). 
5. D. Manvsll, L.M. Ballarin, H. Stapeldt. SADMAN-Combining measurements and calculations to map noise in Madrid. (The 33 th international congress and exposition on noise control engineering, 2004)

6. K. Kennth, D. Eddie, C. James. Sound Vib (2007)

7. A.V. Kostsov, I.A. Bakhirev, E.N. Borovik, D.S.Martyakhin, Transport planning of cities. Tutorial. (Moscow:A-project, 2017)

8. G.A. Mendeleev, Transport in urban planning. (M: Transport, 2005)

9. Data of the Unitary Enterprise "Road Project Expertise" of the State Committee for Motor Roads of the Republic of Uzbekistan, https://unece.org/DAM/env/epr/epr_studies/ECE.CEP.188.Eng.pdf

10. Data of the traffic control department of the Traffic Safety Department of the Tashkent City Main Department of Internal Affairs, https://iibb.uz/en/menu/toshkent-shaar-iibbaida

11. Information of the Tashkent City Department of Landscaping on "Dislocation of the forces under the use, maintenance and repair of the central forces of the city of Tashkent and the district landscaping departments", Tashkent 2018.

12. Y.F.Zhang, X.J. Deng. Road traffic environment engineering (China commun Press, 2001)

13. A.T. Khotamov, A.F. Shaxidov, City streets, roads and transport. (TAQI, 2020)

14. A.T. Khotamov, F.A.Abdixalilov, Architecture-Construction-Design, 2, 16 (2019)

15. A.T. Khotamov, N.Z. Tolipova, Architecture. Construction. Design, 1-2, 36 (2018) 